\title{
Clinicopathological Studies of Some Non-Alzheimer Dementing Diseases
}

\author{
David Munoz-Garcia and Samuel K. Ludwin
}

\begin{abstract}
The brains of most demented patients show at autopsy the lesions of Alzheimer's disease (AD). However, the brains of other demented patients show either no morphological changes or lesions distinct from those of AD. We report clinicopathological studies on two diseases in this latter group. The study of these diseases can improve our understanding of $\mathrm{AD}$.

Pick's disease is characterized by dementia, lobar cerebral atrophy, and neuronal cytoplasmic inclusions. Most cases, which we have called "classical", show inclusions made up of straight fibrils that are immunologically cross-reactive with the paired helical filaments of AD. In other "generalized" cases, similar fibrils are coated by granular material and are less reactive with anticytoskeletal antibodies.

In contrast to the cytoplasmic localization of the lesions in Pick's disease, it is the cell nucleus that shows abnormalities in neuronal intranuclear hyaline inclusion disease. This disease can present clinically as dementia of adult onset. Thus, either nuclear or cytoplasmic lesions can produce a pattern of neuronal dysfunction resulting in dementia.
\end{abstract}

RÉSUMÉ: Etudes clinicopathologiques de certaines maladies de type non-Alzheimer occasionnant de la démence. Le cerveau de la plupart des patients déments présente des lésions caractéristiques de la maladie d'Alzheimer (MA) à l'autopsie. Cependant, le cerveau d'autres patients déments ne présente pas de changement morphologique ou présente des lésions différentes de celles de la MA. Nous rapportons des études clinicopathologiques au sujet de deux maladies de cette dernière catégorie. L'étude de ces maladies peut améliorer notre compréhension de la MA.

La maladie de Píck est caractérisée par de la démence, de l'atrophie au niveau des lobes cérébraux et des inclusions cytoplasmiques dans les neurones. La plupart des cas que nous avons désignés comme "classiques", comportent des inclusions constituées de filaments droits qui présentent une réaction immunologique croisée avec les filaments héliocïdes groupés par paires. Chez d'autres cas "généralisés", des fibrilles analogues sont enduites d'une matière granulaire et réagissent moins en présence d'anticorps dirigés contre le squelette cellulaire.

Contrairement à ce qui se passe dans la maladie de Pick où les lésions sont localisées au niveau du cytoplasme, ce sont les noyaux cellulaires qui sont anormaux dans la maladie comportant des inclusions hyalines intranucléaires dans les neurones. Cette maladie peut se présenter comme une démence survenant à l'âge adulte. Ainsi, soit les lésions nucléaires ou cytoplasmiques peuvent produire un pattern de dysfonction neuronale conduisant à la démence.

Can. J. Neurol. Sci. 1986; 13:483-489

It has been estimated that the brains of about $70 \%$ of patients with dementia show the lesions of Alzheimer's disease at postmortem. ${ }^{1}$ The balance of the dementias is due to the variety of causes, including traumatic, toxic, metabolic, infectious, and vascular insults, as well as a number of relatively uncommon neurodegenerative diseases, that is, diseases of unknown cause characterized by progressive systematized loss of neurons. Clinicopathological comparison of these rarer neurodegenerative diseases with Alzheimer disease, itself a neurodegenerative disease, may improve our understanding of the pathogenetic mechanisms that underlie these maladies. Clinically, the numer- ous studies being conducted on pathophysiology and treatment of Alzheimer's disease have increased the need for a definitive diagnosis of $\mathrm{AD}$ during life, preferably without invoking cerebral biopsy. Although it is generally possible to exclude by laboratory and radiological methods most of the non-Alzheimer causes of dementia mentioned above, differentiation between the diverse neurodegenerative diseases remains at best uncertain. At the present time, improvements on diagnostic accuracy must be based on careful delineation of clinicopathological subgroups. We are presenting here two such clinicopathological correlation studies in organic dementias. One of these 
disorders, Pick's disease is associated with neuronal cytoplasmic inclusion, whereas the other disease is characterized by eosinophilic inclusions in the neuronal nuclei.

\section{Pick's Disease}

Pick's disease is one of the organic dementias associated with characteristic gross and histopathological findings at autopsy. Although there is not universal agreement on the diagnostic criteria in this entity, for our studies we have defined Pick's disease by the presence of a history of dementia with onset in adult life, a pattern of cortical atrophy similar to that described by A. Pick, ${ }^{2}$ and argyrophilic ball-shaped inclusions within the neuronal cytoplasm. ${ }^{3}$ In our original report on six patients, ${ }^{4}$ we proposed the existence of classic and generalized variants of Pick's disease. The two variants differ on the distribution of the atrophy and the characteristics of the inclusion bodies. Additionally, in that initial series, the generalized cases occurred in younger patients than the classic cases. Since then, four additional cases have been collected, three of which fall into the classical variant. The patients are summarized in Table 1 .

\section{Classic variant}

Four men and two women comprise the classical group in this series. The average age at death was 69.8 years, with range 54 to 80 years. Patients were brought to medical attention 7 to 14 years (average 10.8 years) before death, but symptoms may have started earlier. The initial symptoms were always of psychiatric nature: anxiety, withdrawal from family, friends, and hobbies, flat affect, inappropriate behaviour, depression, rarely accompanied by delusions. Psychometric testing at early stages showed preservation of Memory Scales. Language difficulties were common: these included groping for words, paraphasia, stereotyped responses to questions, and difficulty to follow complex commands. This usually progressed to mutism well before the demise of the patient. Extrapyramidal motor signs, in the form of flexed stance, clumsiness, and dystonic fixed posturing of the extremities, often in a not entirely symmetrical fashion, were frequently mentioned in the charts relatively late in the course of the disease. The daily activities of the late, uncommunicative patients were dominated by belligerence, incontinence, and a tendency to put any object within reach in their mouths. They often spat their food and ate it again. Death, in a bedridden terminal state, was usually due to infections.

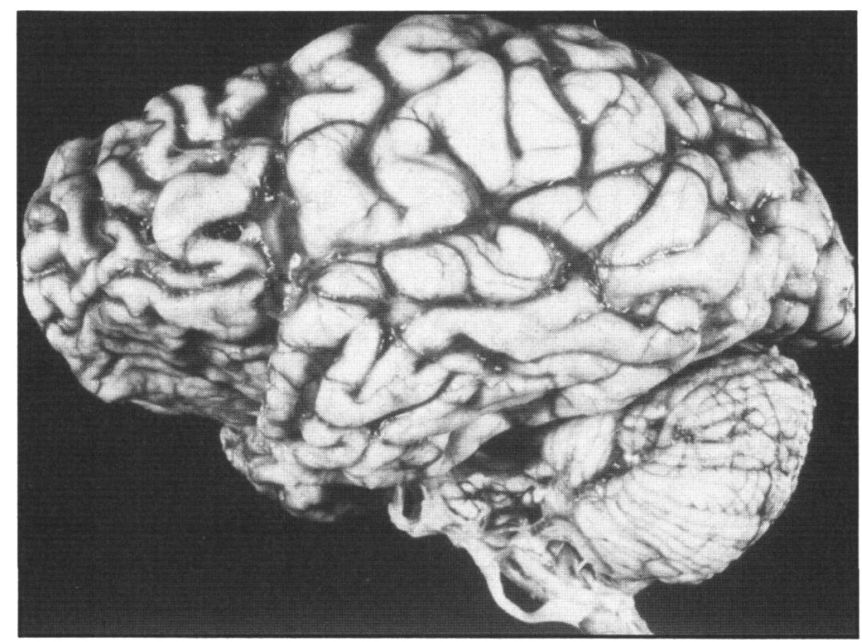

Figure 1 -Marked fronto-temporal atrophy in contrast to the normal appearance of the posterior regions of the brain. Classical Pick's disease.

Laboratory studies were not helpful other than to exclude other causes of dementia. The EEG usually showed slow wave dysrhythmia over the temporal regions, sometimes in an asymmetric fashion, but no slowing of the occipital alpha rhythm.

The brain weights, available in 5 patients, ranged from $675 \mathrm{~g}$ to $1190 \mathrm{~g}$, average $947 \mathrm{~g}$. All brains showed marked frontotemporal and anterior cingulate cortical atrophy (Figure 1), but the precentral gyri were nearly normal. The atrophy always involved the hippocampal formation, whereas the parietal and occipital lobes, and posterior half of the superior temporal gyri were spared. The caudate nuclei were normal or, in two cases, slightly flattened, and other subcortical nuclei, including the substantia nigra appeared unremarkable. Microscopically, the atrophic cortex showed loss of over $90 \%$ of the neurons, spongiosis of the neuropil in the upper layers, and marked astrocytosis. Characteristically, rounded, compact neuronal cytoplasmic inclusions were found, that were intensely stained by silver stains, like Bielchowsky or Bodian (Figure 2), but not with the Congo Red stain for amyloid, nor with the methyl green pyronin and acridine orange stains for RNA (Figure 2). These inclusions (Pick bodies) were scattered through the atrophic cortex and were best seen at the border between the atrophic and normal cortex. They were specifically abundant in

\section{Table 1 .}

\begin{tabular}{|c|c|c|c|c|c|c|c|c|c|}
\hline & \multirow[b]{2}{*}{ Sex } & \multirow[b]{2}{*}{$\begin{array}{c}\text { Age } \\
\text { Onset- } \\
\text { Death }\end{array}$} & \multirow[b]{2}{*}{$\begin{array}{c}\text { Brain } \\
\text { Weight }\end{array}$} & \multicolumn{4}{|c|}{ ATROPHY } & \multicolumn{2}{|c|}{ PICK BODIES } \\
\hline & & & & $\begin{array}{c}\text { Neocortex } \\
\text { Frontal- } \\
\text { temporal }\end{array}$ & Thalamus & Caudate & Nigra & $\begin{array}{c}\text { Present in } \\
\text { Hippocampus }\end{array}$ & $\begin{array}{c}\text { Argyophilia } \\
\text { (S) strong } \\
\text { (W) weak }\end{array}$ \\
\hline 1) & $\mathrm{F}$ & $57-69$ & 970 & +++ & - & + & - & + & $\mathrm{S}$ \\
\hline 2) & $\mathbf{M}$ & $56-63$ & $?$ & +++ & - & - & - & + & $\mathrm{S}$ \\
\hline 3) & $\mathrm{F}$ & $?-74$ & 1190 & $+t+$ & - & - & - & + & $\mathrm{S}$ \\
\hline 4) & $\mathbf{M}$ & $29-39$ & 1070 & +++ & ++ & $+t+$ & ++ & - & $W$ \\
\hline 5) & $\mathbf{M}$ & $30-35$ & 1180 & $+t+$ & ++ & $++t$ & ++ & - & W \\
\hline 6) & $\mathbf{M}$ & $60-74$ & $?$ & $+t+$ & & & & - & $W$ \\
\hline 7) & $\mathbf{M}$ & $?-80$ & 1150 & $+t+$ & - & - & - & + & $\mathbf{S}$ \\
\hline 8) & $\mathrm{M}$ & $40-54$ & 1100 & +++ & - & - & - & + & $\mathbf{S}$ \\
\hline 9) & $\mathbf{M}$ & $69-79$ & 675 & $++t$ & - & + & - & + & $\mathrm{S}$ \\
\hline 10) & $\mathrm{F}$ & $51-59$ & 830 & $+t+$ & $+t$ & ++ & ++ & - & $W$ \\
\hline
\end{tabular}

Cases 1 - 6 correspond to those in Reference 4 .

Cases $1-3$ and $7-9$ are classical, 4, 5, and probably 6 are generalized, and 10 is generalized with abundant swollen chromatolytic neurons. 


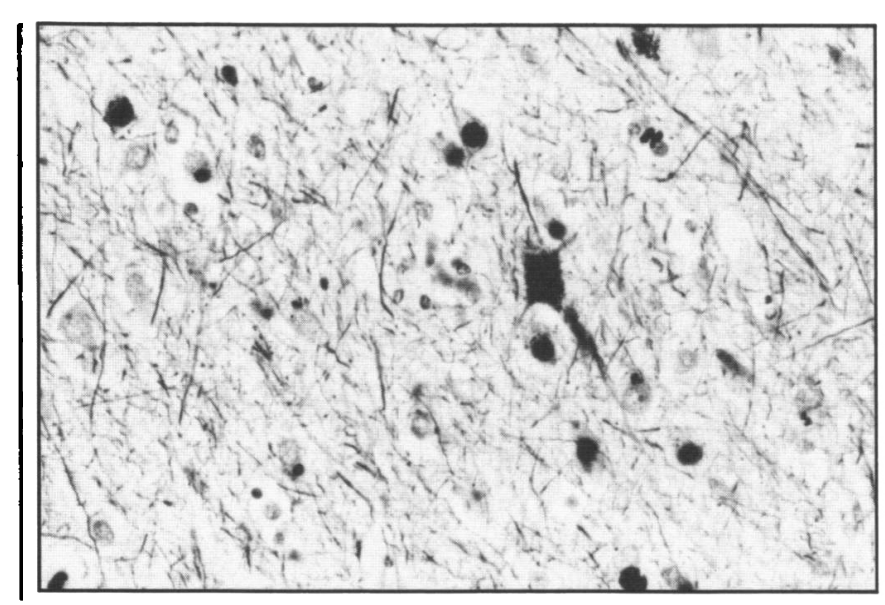

Figure 2 - The argyrophilic globules in the neuronal cytoplasm are Pick bodies. In addition, a homogeneously stained swollen neuron is seen near the center of the photograph. Case 7, frontal cortex, Bielchowsky silver stain. $\times 260$

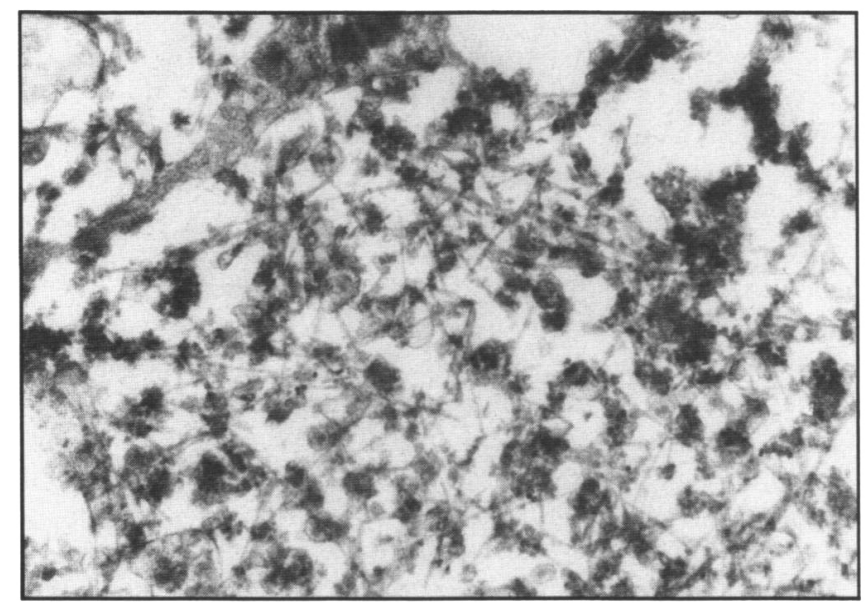

Figure 3 - This electron microscopic photograph illustrates the border between a classic Pick body below and the normal cytoplasm above. Notice that the straight fibrils criss-crossing within the Pick body are devoid of side arms. The organelle above and to the left of the Pick body is a mitochondrion. Case 3. $\times 40700$

the fascia dentata and Sommer sector of the hippocampal formation. Ultrastructurally, the inclusions were non membranebound and were predominantly made up of criss-crossing straight fibrils, devoid of side arms, with an average diameter of $15 \mathrm{~nm}$ (Figure 3). In this region, normal organelles had been replaced by vesicles, degenerated mitochondria, and granular material. The morphology of these fibrils is distinct from normal neurofilaments, ${ }^{5-8}$ which in the past have been thought to be the component of Pick bodies. ${ }^{9-10}$ In a few inclusions there were, among the straight fibrils, rare, isolated, periodically twisted fibrils, with a larger period than the paired helical filaments (PHF) seen in neurofibrillary tangles. These two types of fibrils have now been observed in the SDS-insoluble residue from homogenates obtained from Pick's disease brains." Therefore, Pick body fibrils resemble paired helical filaments of the neurofibrillary tangle of Alzheimer's disease by the unusual property of insolubility in boiling SDS. ${ }^{12}$

We were suprised by the fact that in spite of the different ultrastructural appearance, Pick bodies and Alzheimer neurofibrillary tangles showed the same reactions with antibodies

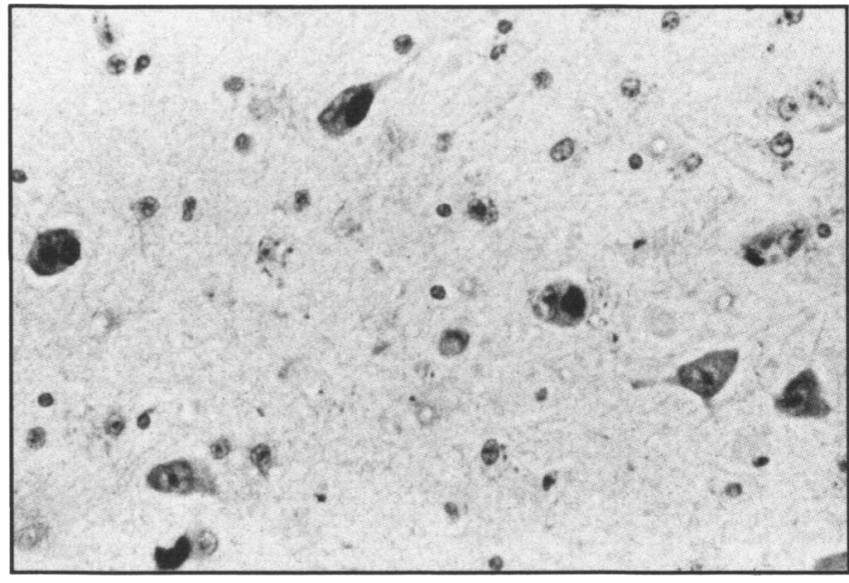

Figure 4 - Decoration of classic Pick bodies with antimicrontubule antiserum. visualized by the avidin-biotin technique. Case 9, hippocampus. .x260

directed against cytoskeletal elements. Pick bodies were intensely labelled with the monoclonal antibody $07-5$ directed against a phosphorylated epitope in the $200 \mathrm{kD}$ protein of the neurofilament triplet. ${ }^{13}$ Phosphorylated neurofilaments are not present in the perikaryon of normal neurons, but Alzheimer neurofibrillary tangles are stained with $07-5$ and other antibodies directed against phosphorylated neurofilament epitopes ${ }^{14}$. Probst et al ${ }^{15}$ have also reported identical immunoreactivity of Alzheimer neurofibrillary tangles and Pick bodies with a series of monoclonal antibodies against neurofilament proteins. Their finding (and our unpublished observation) that Pick bodies fail to react with several polyclonal antisera against neurofilament proteins is inconsistent with the hypothesis that the fibrils which Pick bodies are made of are normal neurofilaments.

Pick bodies were also intensely stained with a polyclonal antiserum against microtubules purchased from Miles Yeda (Figure 4). Although this antiserum was prepared against purified chicken brain tubulin, immunoblotting studies have shown that it reacts strongly with several microtubule associated proteins, and that this latter component of the antiserum was responsible for its reactivity with neurofibrillary lesions. ${ }^{16}$ Rasool and Selkoe ${ }^{8}$ have shown that Pick bodies were recognized by a polyclonal antibody prepared against SDS-insoluble paired helical filaments of Alzheimer neurofibrillary tangles. Dickson et al ${ }^{17}$ confirmed this result using a monoclonal antibody raised against Alzheimer neurofibrillary tangles in one of two patients.

In addition, scattered in the deep layers of the abnormal neocortex there were cells with swollen, homogeneously fine granular, pink cytoplasm and eccentric nucleus. These cells were variably reactive with silver stain (Figure 2). Accordingly, their ultrastructural appearance was not homogeneous, some giving the impression of an oversized Pick body made up of the same constituents as the rounded inclusions, whereas in others the accumulation of normal neurofilaments, mitochondria, endoplasmic reticulum and ribosomal rosettes was reminiscent of the morphology of central chromatolysis.

Hirano bodies and granulovacuolar degeneration were conspicuous in the hippocampus in every case, and a few neurofibrillary tangles, ultrastructurally identical to those of Alzheimer's disease were commonly seen in the $\mathrm{H} 1$ and $\mathrm{H} 2$ segments of the Cornu Ammonis. 


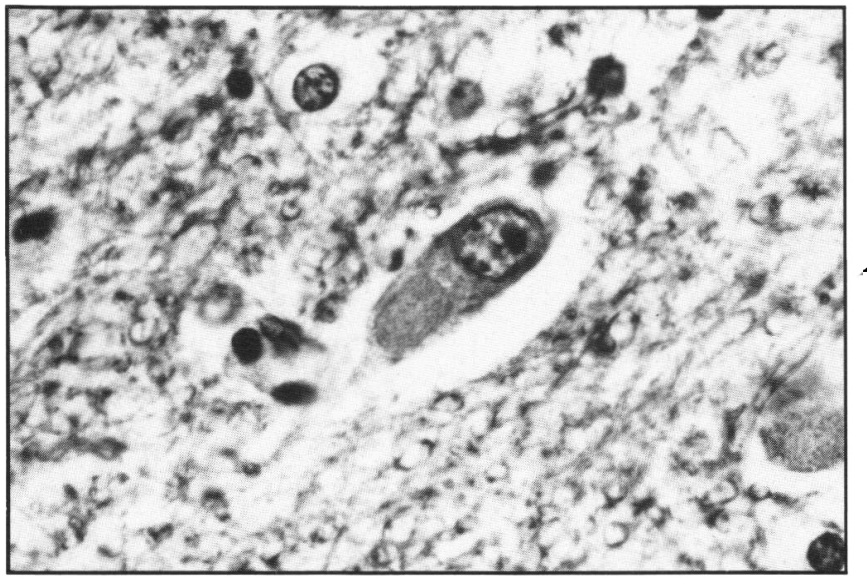

Figure 5 - The inclusions in the generalized variant cases are more conspicuous on H\&E staining, and are found in subcortical structures. Case 4. subthalamic nucleus, $H \& E$. $x 650$

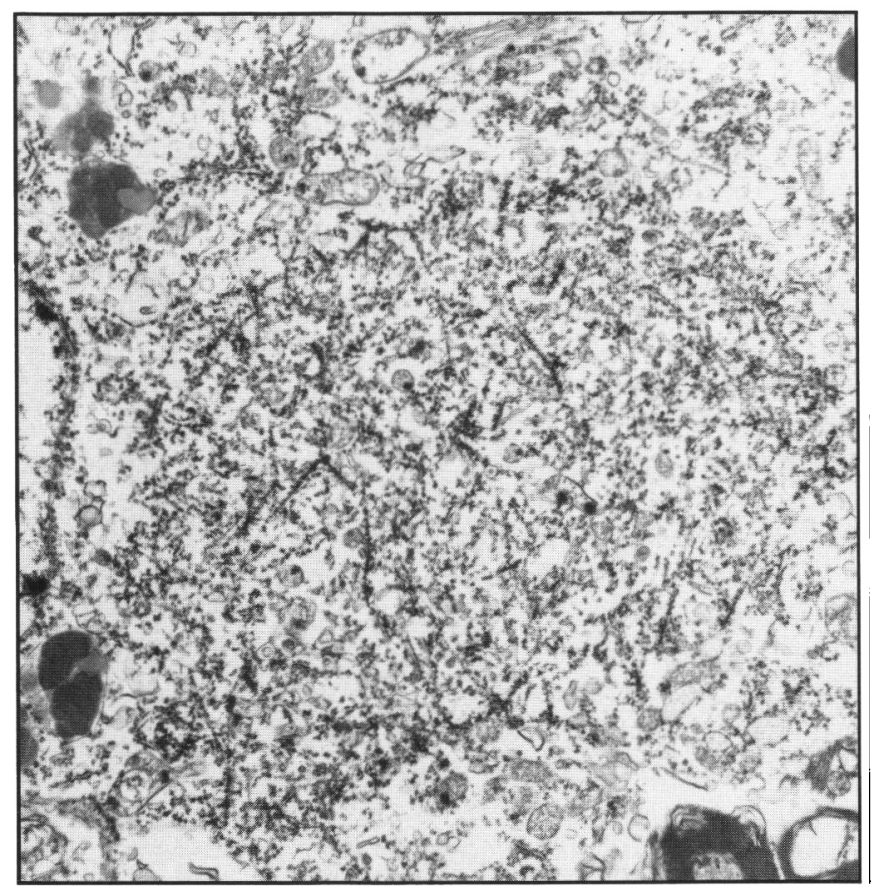

Figure 6-A generalized variant type of Pick body is seen here to the right of the neuronal nucleus. The constituent fibrils are more electron dense than those of the classic variant, because they are coated by electron-dense material. Case 4, subthalamic nucleus.

\section{Generalized variant}

In our previous report, ${ }^{4}$ we described two demented patients in whom, in addition to the lobar pattern of atrophy and widespread presence of neuronal cytoplasmic inclusions, the atrophic process extended beyond the cerebral cortex to involve the neostriatum, the thalamus, and the substantia nigra. We referred to these cases as the "generalized" variant of Pick's disease, as distinct from the "classic" variant described above. In contrast to the classic variant, in the generalized variant the dentate fascia of the hippocampal formation appears normal, and no inclusions are found in the hippocampal pyramidal layer. The inclusions in the generalized variant cases (Figure 5) had a higher RNA content (as defined by histochemistry), and were less reactive with silver and antibodies directed against the cytoskeleton than the Pick bodies of the classical cases. This may well be related to the ultrastructurally observed coating of the constituent fibrils of the inclusion by electron dense granular material, probably derived from ribosomes (Figure 6). In spite of the greater extent of the atrophy in the generalized than in the classic variant, we have not been able to find consistent deviations in the clinical syndromes exhibited by generalized patients as compared to classic patients, other than the younger age of onset of the former.

Our generalized variant cases may be similar to those reported as dementia with cortical Lewy bodies ${ }^{18-20}$ and amyotrophic lateral sclerosis with neuronal intracytoplasmic inclusions. ${ }^{21}$ The differences recently described by Clark et $\mathrm{al}^{22}$ between cortical Lewy bodies and Pick bodies are based on subjective impressions of colour and hyaline appearance at the $H \& E$, light microscopic level only. Additional comparative immunocytochemical studies in these diseases may be able to clarify this issue.

\section{Inclusions in swollen neurons only variant}

One additional patient (case 10) who fulfills our criteria for Pick's disease, but does not fit in either of the two variants discussed above will now be described.

A woman with no known family history of neurological disease started to show bizarre behaviour at age 51 . She refused to bathe, would change the clock to the hour she wanted it to be, and discussed intimate details with strangers. Later she became belligerent with her grandchildren. By age 56 she was unable to engage in conversation, or even name objects, but she was able to read aloud, correctly, although she could not repeat what she had just read. A CT scan done at this time showed "moderate cortical atrophy". Her final admission to hospital, at age 59, was in a state of dehydration, fever, and multiple infected decubitus ulcers. She was found to have bilateral Babinski responses. She died from septicemia shortly after admission.

The brain weighed $830 \mathrm{~g}$, and showed severe frontotemporal atrophy, more pronounced frontally, with sparing of the parietal and occipital lobes. In addition, the caudate nuclei and the thalami were atrophic, and the substantia nigra was depigmented. Microscopically, the expected neuronal loss and astrocytosis was present in the atrophic cortical and subcorti-

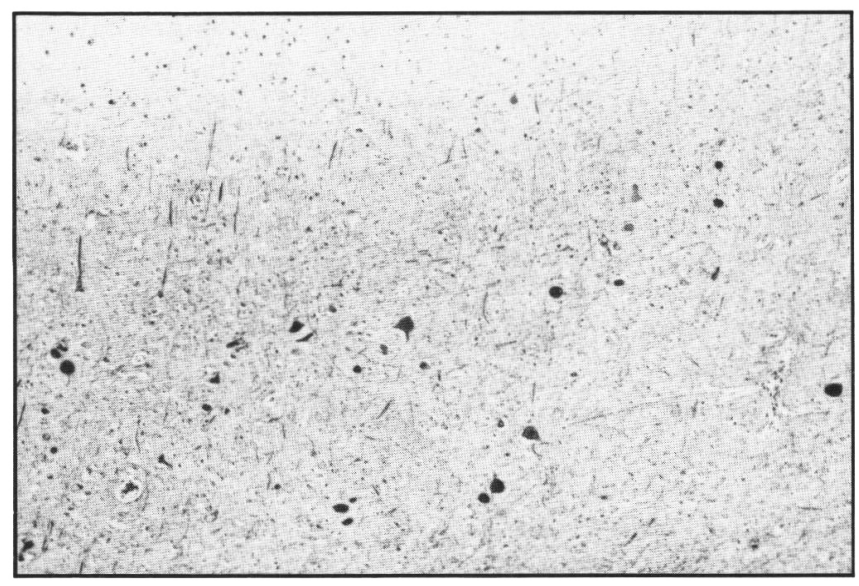

Figure 7-A low power view of the frontal cortexillustrates the abundance of argyrophilic swollen neurons in the deep layers in case 10 . In contrast no argyophilic deposits are seen in the upper layers toward the top of the figure. $x 40$ 
cal areas mentioned above. Scattered throughout the deep layers of the neocortex there were many swollen argentophilic neurons (Figure 7), as described in the classical cases. In the cytoplasm of a few of these neurons there was a rounded silver-positive inclusion with somewhat fuzzy margins. Similar neurons were seen in the caudate, thalamus, and subthalamus. Several neurons in the substantia nigra showed cytoplasmic inclusions, either basophilic or eosinophilic, the latter resembling Lewy bodies. The hippocampal formation, on the other hand, was entirely normal.

Case 10 belongs with what Constantinidis et $\mathrm{al}^{23}$ call "group B' 'in their classification of Pick's disease, which they define as formed by those patients whose brains showed swollen neurons, but no argyrophillic inclusions. The argyrophilic material in some swollen neurons in our case 10 had concentrated in the center of the cytoplasm to form an inclusion resembling a Pick body, and therefore we considered that our criteria for inclusion in the series were fulfilled. However, Pick bodies were never seen in non-swollen neurons in this case. Clark et $\mathrm{al}^{22}$ have addressed this issue in a recent paper on the relationship between cortical degeneration with swollen chromatolytic neurons and Pick's disease. They felt that the large, soft-edged inclusion in swollen neurons are different from classic Pick bodies. This conclusion is supported by the different distribution of the inclusions: classical Pick bodies occur in the upper cortical layers and the hippocampus, whereas swollen neurons with argyrophilic inclusions are found in the deep layers of the cortex and not in the hippocampus. In addition, the ballooned cells can be stained with polyclonal antisera against the 210000 and 155000 dalton neurofilament proteins, whereas classic Pick bodies are not reactive with these antisera. ${ }^{15}$

The distribution of the atrophy, sparing of the hippocampal formation, and the presence of inclusions in subcortical structures in case 10 are very similar to that of the "generalized" cases in our series. This is not an isolated feature, since Constatinidis et $\mathrm{al}^{23}$ state that the atrophy of group B cases extended beyond the anterior cortex to include the precentral gyrus and the basal ganglia. Moreover, Clark et al $^{22}$ description of the ultrastructure of the swollen neurons in their cases is consistent with our findings in the generalized patients. However, the extraordinary abundance of swollen neurons in the cortex of case 10 was not seen previously in our material, and the generalized cases showed cytoplasmic inclusions in small non-swollen neurons in the upper cortical layers, where none was found in case 10. The classification of these cases has been recently discussed in the literature. ${ }^{22,24}$

The relationship between the variants of Pick's disease is as unclear at present as the etiology of the disease. Both problems are unlikely to be clarified by classical pathological methods alone, nor by molecular genetics analysis that fails to take into consideration careful clinicopathological dissection of disease subgroups.

\section{NEURonal INTRANUCLEAR HYALINE INCLUSIONS DiSEASE}

Like Pick's disease, neuronal intranuclear hyaline inclusion disease (NIHID), is a disease defined by the pathology rather than the clinical features. The 15 patients reported in the literature $e^{25-35}$ vary widely in the age of onset and detailed clinical picture, although all of them showed slow progression of neurological symptoms that included, in diverse combinations,

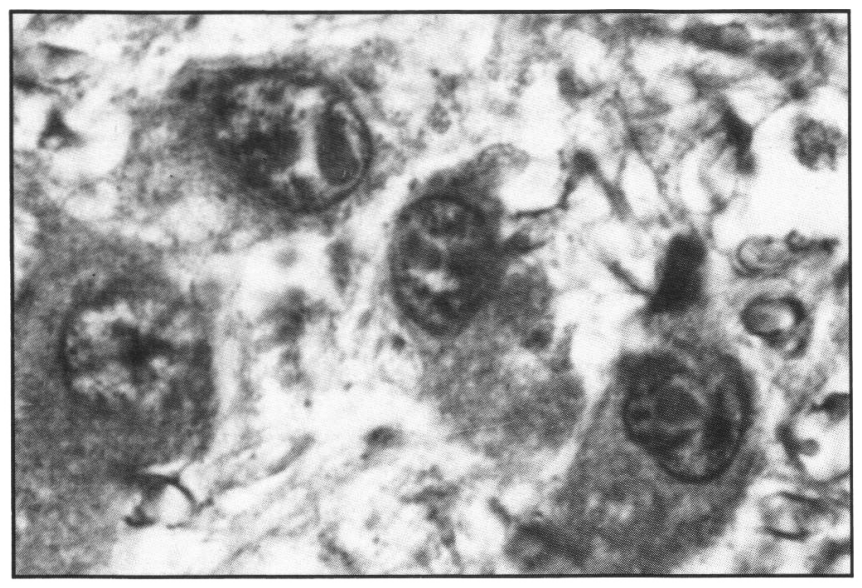

Figure 8 - Intranuclear inclusions are seen in 3 neurons in the dentate nucleus of the cerebellum in a patient with NIHID. The inclusions, surrounded by a halo, are distinct from the nucleolus. $x 650$

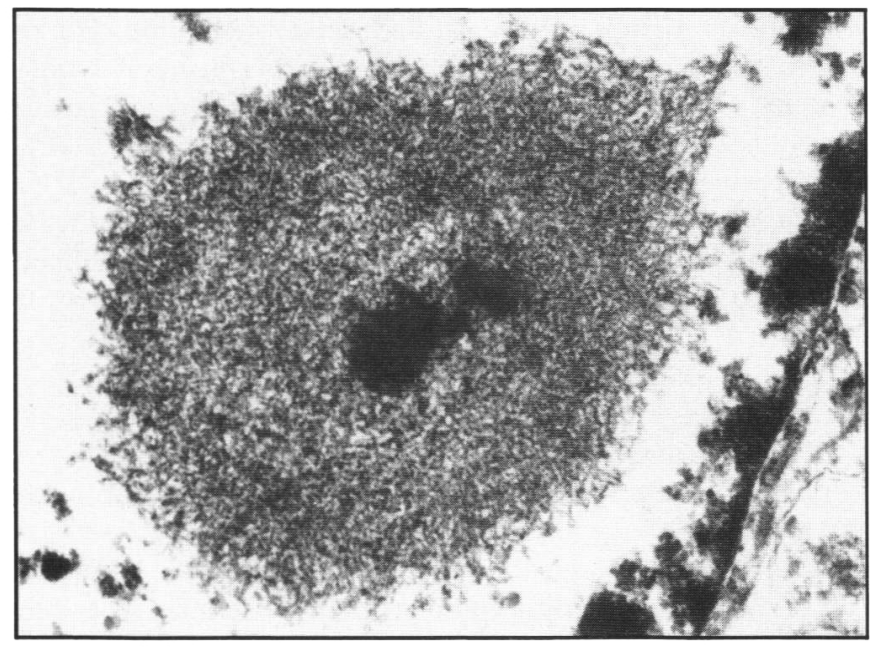

Figure 9 - The nuclear envelope separates the cytoplasm, at the lower right of the figure, from the nucleus of this cortical glial cell of a patient with NIHID. The rounded nuclear incusion is made up of fuzzy fibrilo-gramular material, and contains an electron-dense central core. $x 28800$

mental deterioration, dysphasia, choreoathetosis, ataxia, dysarthria, dysphagia, tremor, and seizures, as well as signs of involvement of the pyramidal tracts and lower motor neurons, and disturbances of the control mechanisms of extraocular movements and pupils, the position sense, and the movements of the gastrointestinal tract. Twelve patients presented before the age of 15 years, and ten of these were dead by 30 years of age, whereas the other two survived to age 65 .

Our two patients ${ }^{36}$, a man and a woman, are unusual in that they had had a normal life until middle age (47 and 56 years, respectively), when they developed a dementing process with additional neurological signs. The man showed arm tremor, truncal ataxia, choreoathetosis, dysarthria, unreactive pupils, and dysphagia. The woman's dementia was accompanied by severe dysphasia, both receptive and expressive, and "fidgeting". Laboratory studies were not helpful in either case. The man died at age 55, and the woman at age 68 .

Both brains showed cortical and caudate atrophy, both grossly and microscopically. The gross pattern of atrophy in the brain of the women was not unlike that of Pick's disease. The distinctive finding was the presence of brightly eosinophilic hyaline 
inclusions in the nuclei of neurons and glial cells in the brain (Figure 8), dorsal root ganglia, and peripheral autonomic ganglia. Ultrastructurally, the inclusions were made of ill-defined, crisscrossing fibrils and granular material, and were often centered by an electron dense core, sometimes mineralized (Figure 9). Although Palo et $\mathrm{al}^{37}$ have reported that the inclusions in the isolated neuronal nuclei of their sibling patients were reactive with antineurofilament antisera, we did not observe this immunocytochemical reaction in our sections. However, the inclusions were found in neurons only in the patients of Palo et al, ${ }^{37}$ as they were in five of the cases reported in the literature. It would have been surprising to find neurofilaments in the nuclei of glial cells; the astrocytic inclusions did not react in situ with antibodies against the astrocytic-specific intermediate filament protein, GFAP, either.

The diversity of clinical presentations, areas of the brain, and particularly cell types involved, suggests that these nuclear inclusions represent a cellular response that can be induced by several insults. Similarly, neurofibrillary tangles can be found not only in Alzheimer disease and Down syndrome, but in processes of clearly different etiology, such as repeated trauma (Dementia pugilistica ${ }^{38}$ ), infection (subacute sclerosing panencephalitis ${ }^{39}$ ), and genetic determination (tuberous sclerosis ${ }^{40}$ ).

Interestingly, there may be a connection between NIHID and Pick's disease: Seitelberger et $\mathrm{al}^{5}$ briefly have described a 74 year old male patient (case 20 ) with Pick's disease as defined by our criteria and eosinophilic nuclear inclusions in neurons and glia.

\section{Conclusion}

A first step in research in the complex field of dementia is the separation of discrete clinicopathological entities. The hope that immunocytochemistry would provide a powerful classification tool has not yet been realized. On the other hand, by emphasizing the similarities rather than the differences between the different forms of neurofibrillary pathology, the molecular approach to morbid anatomy has raised new questions. For example, the immunological cross-reactivity of Pick bodies and Alzheimer neurofibrillary tangles suggests that despite the clinical, gross anatomical, light microscopical, and ultrastructural differences between them, the two diseases share mechanisms by which normal components of the cytoskeleton become transformed into insoluble fibrils. The comparison of the immunocy tochemically indistinguishable Pick bodies with Alzheimer neurofibrillary tangles offers an opportunity to explore how the latter acquire the properties of amyloid.

\section{ACKNOWLEDGEMENTS}

We thank Dr. J. McQuillen and Dr. B. Little for providing us with additional cases.

\section{REFERENCES}

1. Terry RD, Katzman R. Senile dementia of the Alzheimer type. Ann Neurol 1983; 14: 497-506.

2. Pick A. Ueber einen weiteren Symptomenkomplex im Rahmen der Demential senilis, bedingt durch umschriebene starkere Hirnatrophie (gemischte Apraxie). Monatsschr Psychiatr Neurol 1906; 19: 97-108.

3. Alzheimer A. Ueber eigenartige Krankheistfalle des spateren Alters. Zentralbl Gesamte Neurol Psychiatr 1911; 4: 356-385.

4. Munoz-Garcia D, Ludwin SK. Classic and Generalized variants of Pick's disease: A clinicopathological, ultrastructural, and im- munocytochemical comparative study. Ann Neurol 1984; 16: 467-480.

5. Seitelberger F, Gross H, Pilz P. Pick's disease: a neuropathological study. In: Hirano A, Miyoshi $\mathrm{K}$ eds. Neuropsychiatric Disorders in the Elderly. New York, Igaku-Shoin 1982; 118-126.

6. Oyanagi S. Ultrastructural comparison between Pick bodies and the neurofibrillary changes in Alzheimer's disease and progressive supranuclear palsy. In: Hirano A. Miyoshi K eds. Neuropsychiatric Disorders in the Elderly. New York, Igaku-Shoin, 1983; 87-117.

7. Shibayama $\mathrm{H}$, Kitoh J, Marui Y, et al. An unusual case of Pick's disease. Acta Neuropathol (Berl) 1983; 59: 79-87.

8. Rasool CG, Selkoe DJ. Sharing of specific antigens by degenerating neurons in Pick's disease and Alzheimer's disease. $\mathrm{N}$ Eng $\mathrm{J}$ Med 1985; 700-705.

9. Wisniewski HM, Coblentz JM, Terry RD. Pick's disease: a clinical and ultrastructural study. Arch Neurol 1972; 26: 97-108.

10. Brion S, Mikol J. Etude ultrastructurale de la maladie de Pick: a propos de trois cas. Rev Neurol (Paris) 1971; 125: 273-286.

11. Sparkman DR, Hammon K, Johnson S, et al. Pick disease: purification of neuronal Pick fibrils. Society for Neuroscience Abstracts 1985; 11: 167.

12. Selkoe DJ, Ihara Y, Salazar FJ. Alzheimer's Disease: Insolubility of partially purified paired helical filaments in sodium dodecyl sulfate and urea. Science 1982; 215: 1243-1245.

13. Sternberger LA, Sternberger NH. Monoclonal antibodies distinguish phosphorylated and non-phosphorylated forms of neurofilaments in situ. Proc Natl Acad Sci USA 1983; 80: 6126-6130.

14. Sternberger NH, Sternberger LA, Ulrich J. A berrant neurofilament phosphorylation in Alzheimer disease. Proc Natl Acad Sci USA 1985; 82: 4274-4276.

15. Probst A, Anderton BH, Ulrich J, et al. Pick's disease: An immunocytochemical study of neuronal changes. Acta Neuropathol (Berl) 1983; 60: 175-182.

16. Perry G, Rizzuto N, Autilio-Gambetti L, et al. Paired helical filaments from Alzheimer disease patients contain cytoskeletal components. Proc Natl Acad Sci USA 1985; 82: 3916-3920.

17. Dickson DW, Kress Y, Crowe A, et al. Monoclonal antibodies to Alzheimer neurofibrillary tangles. 2. Demonstration of a common antigenic determinant between ANT and neurofibrillary degeneration in progressive supranuclear palsy. AJP 1985; 120: 292-302.

18. Kosaka K. Lewy bodies in cerebral cortex: report of three cases. Acta Neuropathol (Berl) 1978; 42: 127-134.

19. Okezaki H, Lipkin LE, Aronson SM. Diffuse intracytoplasmic ganglionic inclusions (Lewy-type) associated with progressive demential and quadriparesis in flexion. J Neuropathol Exp Neurol 1961; 20: 237-244.

20. Yagishita S, Itoh $Y$, Amano N, et al. Atypical senile demential with widespread Lewy type inclusion in the cerebral cortex. Acta Neuropathol (Berl) 1980; 49: 187-191.

21. Oda M, Akagawa N, Tabuchi $Y$, et al. A sporadic case of the amyotrophic lateral sclerosis with neuronal intracytoplasmic inclusions. Acta Neuropathol (Berl) 1978; 44: 211-216.

22. Clark AW, Manz HJ, White CL, et al. Cortical degeneration with swollen chromatolytic neurons: Its relationship to Pick's disease. N Neuropathol \& Exp Neurol 1986; 45: 268-284.

23. Constantinidis J, Richard J, Tissot R. Pick's disease: histological and clinical correlations. Europ Neurol 1974; 11: 208-217.

24. Case records of the Massachusetts General Hospital, Case 16-1986. N Eng J Med 1986; 314: 1101-1111.

25. Lindenberg R, Rubinstein LJ, Herman MM, et al. A light and electron microscopy study of an unusual widespread nuclear inclusion body disease. Acta Neuropathol 1968; 10: 54-73.

26. Wagener JD, Beggs J, Sidell AD. Virus-like filaments in juvenile parkinsonism. J Neuropathol Exp Neurol 1972; 31: 187.

27. Schuffler MD, Bird TD, Sumi SM, et al. A familial neuronal disease presenting as intestinal pseudoobstruction. Gastroenterol 1978; 75: 889-898. 1961: 61: 309-325.

28. Janota I. Widespread intranuclear neuronal corpuscles (Marinesco bodies) associated with a familial spinal degeneration with cranial and peripheral nerve involvement. Neuropathol Appl Neurobiol 1979; 5: 311-317. 
29. Sung JH, Ramirez-Lassepas M, Mastri AR, et al. An unusual degenerative disorder of neurons associated with a novel intranuclear hyaline inclusion (neuronal intranuclear hyaline inclusion disease). J Neuropathol \& Exp Neurol 1980; 39: 107-129.

30. Michaud J, Gilbert JJ. Multiple system atrophy with neuronal intranuclear hyaline inclusions. Acta Neuropathol 1981; 54: 113-119.

31. Parker JC. Sporadic spinocerebellar degeneration associated with intranuclear neuronal inclusions and arteriosclerotic heart disease. J Neuropathol Exp Neurol 1983; 42: 352.

32. Patel H, Norman MG, Perry TL, et al. Multiple system atrophy with neuronal intranuclear hyaline inclusions. J Neurol Sci 1985; 67: $57-65$.

33. Haltia M, Somer H, Palo J, et al. Neuronal intranuclear inclusion disease in identical twins. Ann Neurol 1984; 15: 316-321.

34. Tateishi J, Nagara $\mathbf{H}$, Ohta $\mathbf{M}$, et al. Intranuclear inclusions in muscle, nervous tissue, and adrenal gland. Acta Neuropathol $1984 ; 63: 24-32$.
35. Soffer D. Neuronal intranuclear hyaline inclusion disease presenting as Friedreich's ataxia. Acta Neuropathol 1985; 65: 322-329.

36. Munoz-Garcia D, Ludwin SK. Adult-onset neuronal intranuclear hyaline inclusion disease. Neurology $1986 ; 36: 785-790$.

37. Palo J, Haltia M, Carpenter S, et al. Neurofilament subunit-related proteins in neuronal intranuclear inclusions. Ann Neurol 1984; 15: $322-328$.

38. Corsellis JAN, Burton CJ, Freeman-Brown D, et al. The aftermath of boxing. Psychol Med 1973; 3: 270-303.

39. Mandybur TI, Nagpaul AS, Pappas Z, et al. Alzheimer neurofibrillary change in subacute sclerosing panencephalitis. Ann Neurol 1977; 1: 103-107.

40. Hirano A, Tuazon R, Zimmerman HM. Neurofibrillary changes, granulovacuolar bodies, and argentophilic granules observed in tuberous sclerosis. Acta Neuropathol 1968; 11: 257-261. 